\title{
La educación centrada en la persona del educando*
}

Julio Perelló**

Antes de hacer una reflexión sobre el centro del encuentro educativo en la persona del educando, quiero expresar mi agradecimiento a los directivos de la Universidad Politécnica Salesiana (UPS). Quiero agradecer este homenaje a mi persona. En primer lugar al Gran Canciller P. Marcelo Farfán, al Rector de la universidad en Ecuador, P. Javier Herrán, a la Directora de la Carrera de Pedagogía, Verónica Di Caudo y a la comisión de comunicación que prepararon este evento laudatorio. También quiero agradecer la presencia de este público selecto.

Hoy no se habla tanto de una 'pedagogía', sino de una 'autogogía', es decir, el educando que se conduce a sí mismo. Este encuentro educativo -conducir desde adentro- nos recuerda mucho el diálogo platónico de los griegos (la educación como un verdadero "parto formativo").

Sinónimos de esta autogogía educativa pudieran ser: deliberación asistida, obstetricia psíquica, conocimiento de sí mismo por la coreflexión, consejo propio del educando estimulado y contrarrestado por una persona cualifi- cada que sería el educador. Se trata de ayudar al educando para que sea capaz de auto-aconsejarse con sus propios recursos, es decir, enseñarle a caminar, orientando el caminar original del educando y no darle razones para que diga -como el adolescente que le reclama a su papá-: "me enseñaste a caminar pero no me dejas caminar".

Para esto no tenemos que olvidar que el objetivo básico del hecho educativo no es solamente llevar al educando a la madurez psicológica, sino también llevarlo a la adultez ética. Y si por educación entendemos "dar la capacidad de obrar el bien (valor ético) con libertad (valor psicológico)", la acción educativa consistirá en el crecimiento psicológico como base de conducción a la libertad y la maduración ética como contenido del mismo hecho educativo.

En general, apuntamos a los valores educativos y no nos interesamos tanto por una metodología de capacitación de dichos valores, con una verdadera capacidad de actuación libre. Comúnmente nos interesamos más por el obrar bien del educando, que por su libertad personal en el obrar bien.

\footnotetext{
Disertación presentada al recibir el Doctorado Honoris Causa otorgado por la Universidad Politécnica Salesiana en Quito, el miércoles 16 de noviembre de 2011 .

** Padre Julio Perelló, sdb. Doctor en Pedagogía por la Universidad Pontificia Salesiana de Roma. Profesor emérito de la Universidad Politécnica Salesiana (UPS) de Quito.
} 


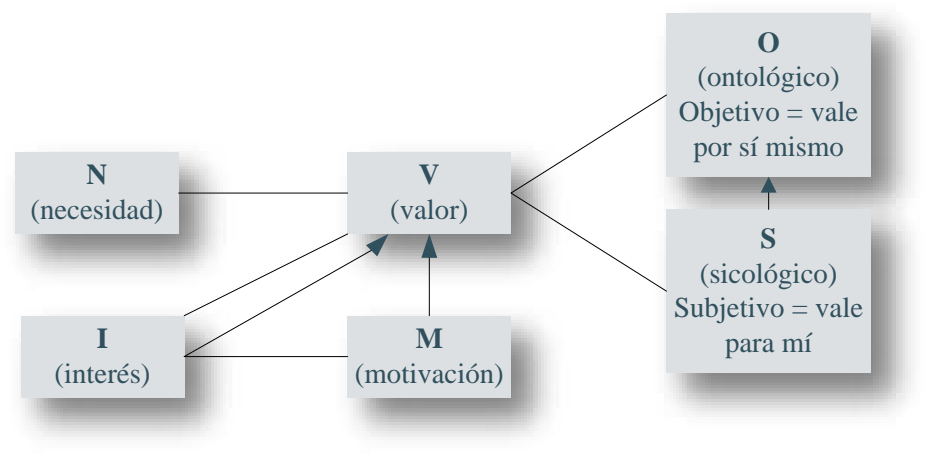

Esta orientación afirma que todo organismo tiene, básicamente, una "tendencia direccional hacia el crecimiento". Ahora nos preguntamos, si todo ser humano goza de esta capacidad autorealizadora, ¿por qué son tan pocos los que se realizan en plenitud? Los defensores de esta orientación pedagógica responden que muchas veces esta tendencia actualizante hacia la madurez psicológica se encuentra bloqueada por valores introyectados o por mecanismos de defensa. Entonces, el educador (en esta orientación) deberá crear un clima propicio para facilitar el desbloqueo, a fin de que la tendencia actualizante pueda obrar libremente.

Este clima lo favorecen tres actitudes básicas del educador: autenticidad, aceptación y comprensión.

\section{Autenticidad}

Esta noción se refiere al estado de acuerdo que existe entre la experiencia, su representación en la conciencia y su comunicación. Estos tres factores son los que intervienen en la actitud de autenticidad. Cuando existe concordancia entre experiencia y conciencia, podemos hablar de congruencia interna o acuerdo interno. Entonces nos referimos al concepto del Yo que, cuando es real, se encuentra integrado y unificado, llegando a ser realmente su Yo profundo.
Cuando existe concordancia entre el Yo real (conciencia y experiencia) y la comunicación que se hace del Yo real, decimos que existe congruencia en la comunicación. Estas congruencias son necesarias para la relación educativa. De aquí se concluye que el educador será auténtico siempre que actúe de acuerdo a su experiencia, tal como la experimenta y siempre que dicha experiencia sea correctamente simbolizada.

El término 'transparencia' recoge la esencia de este elemento. El educador se hace a sí mismo transparente para el educando. La experiencia del educador está abierta a la conciencia y puede ser vivido en la relación y puede ser comunicado si conviene. De esta forma hay una correspondencia entre lo que se está experimentado a un nivel interno (presente en la conciencia) y lo que se le dice al educando.

En una formulación negativa, el educador debe manifestar esta integración en todos los aspectos de su vida, es decir, no debe tomar actitudes defensivas o manipuladoras frente al educando. En este sentido, el "aparentar como si” conduce a una ineficiencia educativa.

\section{Aceptación}

Aceptación no significa aprobación. La aprobación es una manera de juzgar y valorar, lo cual va en contra de los principios de esta orien- 


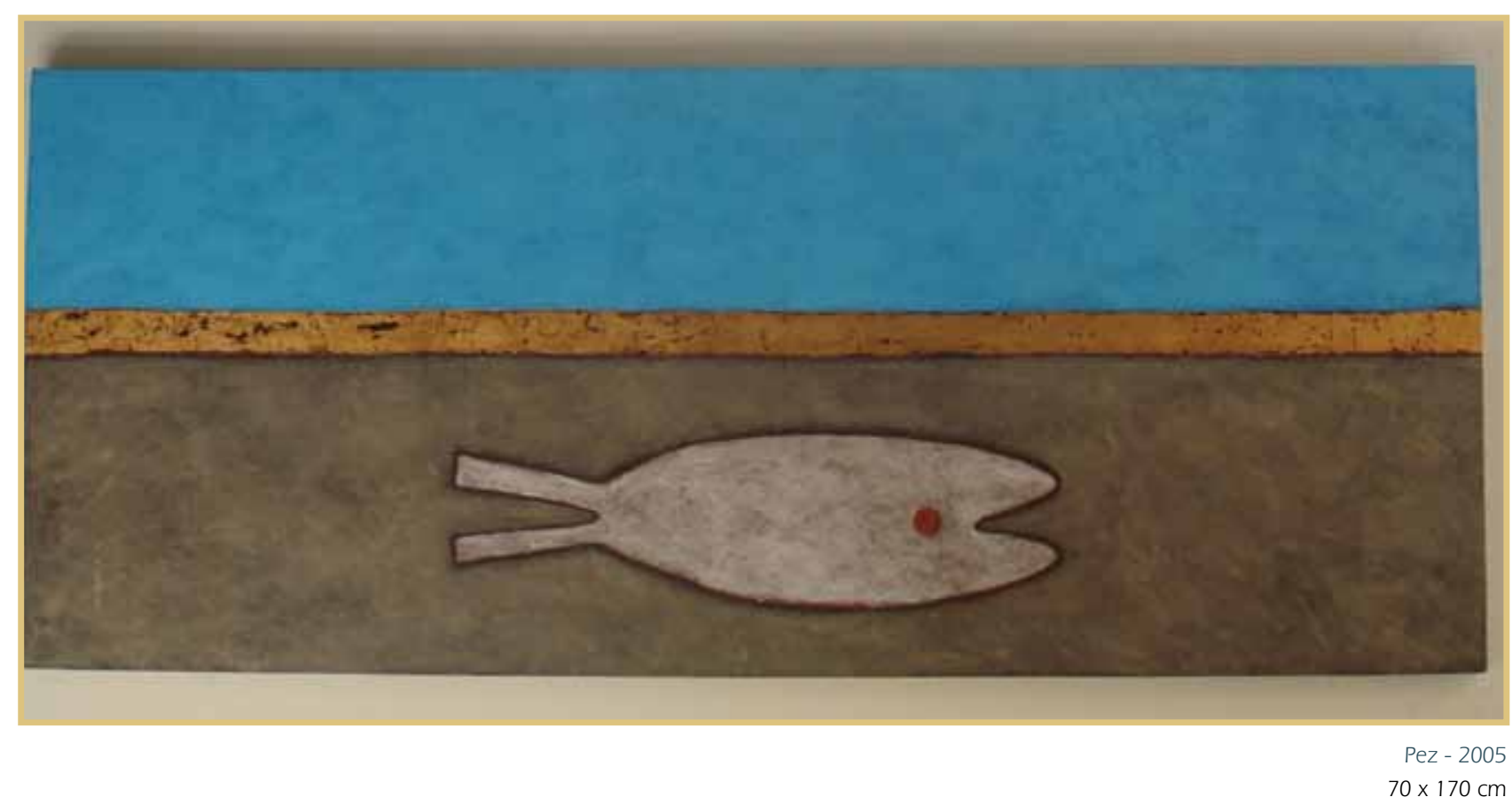

tación educativa. En el lenguaje corriente aceptar significa aprobar, pero en su acepción más profunda no quiere decir 'permitir' ni 'estar de acuerdo'. La aceptación no significa neutralidad ni ausencia.La aceptación es una actitud profundamente positiva y activa hacia el educando. Una actitud de colaboración intensa y de continua presencia a lo que manifiesta el educando.

Aclarados estos equívocos, podemos ahora explicar qué significa 'aceptar':

Detectar la realidad sin interpretarla. Simplemente reconocer que los educandos existen, sin intentar interpretarlos en sus causas o discutirlos en razón de su conveniencia. En otras palabras, el educador atiende sin pronunciarse sobre lo que el educando dice o siente.

Es una actitud de profundo respeto. El educando tiene derecho a sentimientos propios y a descubrirles su propia significación.

Sinónimos del verbo aceptar podrían ser: reconocer, atender, apreciar. $\mathrm{Y}$ en su formulación negativa serían: no negar la realidad, no admirarse, no juzgar, no interpretar, no dar significados a lo que el educando afirma.

Auténtico amor. Amar en este sentido es ponerse a disposición del educando para iluminarlo, para ayudarle a una auto-clarificación. No es un amor posesivo o impositivo, sino donativo. Lo que experimenta el educando es la experiencia de ser amado, no de un modo captativo, sino de un modo que le permite ser una persona distinta, con ideas y sentimientos propios. Se debe amar al educando aunque no se ame lo que hace, lo que piensa y lo que dice.

\section{Comprensión}

Una comprensión empática es el tercer elemento facilitador de esta relación educativa. El término empatía ha sido creado por la psicología clínica para indicar la capacidad de sumergirse en el mundo subjetivo del otro y para participar en su experiencia, en la medida que la comunicación lo permita. Es una de las características más profundas y peculiares de la educación centrada en la persona.

Comprensión empática no significa 'simpatía', la simpatía procede del marco referencial del educador, es decir, sería una actitud condicionada por sus sentimientos y experiencias. Comprensión empática no significa 'identificación', para comprender empáticamente no es necesario vivir y experimentar la realidad del educando.

Lo que permite una profunda comprensión empática del Yo del educador con el Yo del educando es la autenticidad del educador. Cuanta más autenticidad en su Yo, más profundamente podrá penetrar en el mundo subjetivo del otro. Comprensión empática no significa dar 
la razón o estar de acuerdo, más que "darle la razón”, implica "darme una razón” por la cual el otro actúa de determinada manera.

Para comprender empáticamente a una persona, se debe conocer cómo percibe la realidad que motivó su conducta. Hay que tener la capacidad de "ver con sus ojos", es decir, desde su marco referencial interno que está formado por su edad, sexo, cultura, ideología, temperamento...pero sobre todo, por su experiencia irrepetible.

Después de habernos clarificado el sentido auténtico de esta orientación educativa centrada en la persona, vamos a considerar la posibilidad de aplicación de la misma y sus límites en relación al encuentro educativo.

\section{Conclusiones}

- Este modelo de comunicación educativa puede considerarse válido en su aplicación al encuentro educativo como medio para ayudar al educando en su desarrollo psicológico para una personalidad bien estructurada e integrada.

- Este modelo es válido en su aplicación al encuentro educativo ya que no excluye la orientación y comprende actitudes que concuerdan con las requeridas en todo educador para comunicarse con el educando.

- El clima que crea esta orientación, por las actitudes del educador, puede considerarse válido para el encuentro educativo, pues favorece la comunicación de los valores educativos en situación de libertad.

- Esta orientación puede considerarse válida para el encuentro educativo porque contiene en sí misma valores objetivos básicos y proporciona al educando una situación concreta para experienciarlos y asimilarlos con significación autagógica.

- Esta orientación en el campo educativo se encuentra intrínsecamente limitada en cuanto a las exigencias totales del encuen- tro educativo, por no indicar al educando sus fines trascendentales ni ofrecerle un contenido de valores en orden a la educación personal.

\section{Conclusiones finales}

- Las actitudes exigidas en esta orientación autagógica son fundamentalmente propias del hombre adulto y equilibrado. Están dentro de la línea de la personalidad exigida al educador.

- Una serie de respuestas conductuales que normalmente usamos en nuestra relación educativa y que las consideramos favorables para la educación, de hecho, son antipsicológicas y de tipo amenazante frente al educando.

- Una vez suscitada "la comunicación y la circulación" de actitudes aceptantes entre educador y educando (para no caer en un puro psicologismo), se ofrecerán los valores educativos, así, el educando tendrá la posibilidad de aceptar libremente dichos valores y descubrirá la función educativa del educador.

- El educador cristiano, al aceptar y dar confianza al educando, no expresa una iniciativa personal, sino que realiza un ministerio muy significativo. Oden, en su obra "Psicoanálisis y fe cristiana" dice que el hombre es aceptable y digno de confianza porque Dios Padre lo ama y tiene confianza en él. Con esto estamos señalando la función mediadora entre Dios y el educando.

- Esta orientación educativa, centrada en el educando, exige actitudes de base muy importantes y fruto de madurez y equilibrio. No es una técnica, es un modo de ser, por eso no es incumbencia de un educador inexperto, inmaduro o de un simple aficionado de la educación. 